\title{
Infeksi parasit usus pada anak sekolah dasar di pesisir pantai Kecamatan Wori Kabupaten Minahasa Utara
}

\author{
${ }^{1}$ Finka Tangel \\ ${ }^{2}$ Josef S. B. Tuda \\ ${ }^{2}$ Victor D. Pijoh
}

\begin{abstract}
${ }^{1}$ Kandidat Skripsi Fakultas Kedokteran Universitas Sam Ratulangi Manado ${ }^{2}$ Bagian Parasitologi Fakultas Kedokteran Universitas Sam Ratulangi Manado Email: finkatangel12047@yahoo.com
\end{abstract}

\begin{abstract}
Parasite infection is still an endemic disease that can be found in any place in Indonesiathat can cause problems in public health, especially for children in elementary school age. The purpose of this research is to describe the intestinal parasite infection in children at coastal area in Wori district, North Minahasa regency. The method of this research is descriptive survey. The subject of this research is student class I to VI of GMIM Budo and Kima Bajo elementary school in Wori district.The result of this research according to the finding of the stool examination: hookworm infection 4.7\%, Entamoeba coli $39 \%$, Chilomastix mesnili 3.1\%, Blastocystis hominis 3.1\%, Giardia lambia 3.9\% and mixed infection $1.5 \%$.
\end{abstract}

Keywords: intestinal parasite, children, elementary school.

\begin{abstract}
Abstrak: Penyakit akibat parasit usus masih merupakan penyakit endemik yang dapat ditemukan di berbagai tempat di Indonesia yang dapat menyebabkan masalah kesehatan masyarakat, khususnya pada anak yang masih dalam usia sekolah dasar. Tujuan penelitian ini untuk mengetahui gambaran infeksi parasit usus pada anak sekolah dasar di pesisir pantai Kecamatan Wori, Kabupaten Minahasa Utara. Desain penelitian yang digunakan adalah penelitian survei deskriptif.Subjek penelitian ini adalah anak SD GMIM Budo dan SD Negeri Kima Bajo kelas I sampai VI. Hasil penelitian berdasarkan pemeriksaan tinja, didapatkan infeksi cacing tambang 4,7\%, Entamoeba coli 3,9\%, Chilomastix mesnili 3,1\%, Blastocystis hominis 3,1\%, Giardia lambia 3,9\% dan infeksi campuran 1,5\%.
\end{abstract}

Kata kunci: parasit usus, anak SD

Infeksi parasit usus yaitu cacing dan protozoa merupakan masalah kesehatan masyarakat di Indonesia. Cacing usus yang banyak ditemukan adalah soil transmitted helminths (cacing yang ditularkan melalui tanah) yaitu Ascaris lumbricoides, Trichuris trichiura dan cacing tambang, sedangkan protozoa adalah Giardia lamblia dan Blastocystis hominis. ${ }^{1}$

Anak usia sekolah dasar (SD) merupakan kelompok umur yang paling sering terinfeksi oleh parasit usus usus. Hal ini disebabkan karena anak SD paling sering berkontak dengan tanah sebagai sumber infeksi.Defekasi di halaman rumah atau di got dapat menyebabkan tanah tercemar telur cacing dan kista protozoa.Prevalensi infeksi cacing yang ditularkan melalui tanah (soil transmitted helminths/STHs) masih cukup tinggi dan infeksi cacing ini dapat menyebabkan masalah kesehatan masyarakat ${ }^{1-4}$

Penyakit yang disebabkan oleh soil transmitted helminths atau yang lebih dikenal dengan cacing usus merupakan penyakit infeksi paling umum 
yangmenyerang kelompok masyarakat ekonomi lemah.Penyakit akibat cacing dan infestasi protozoa usus sering dikaitkan dengan faktor sanitasi, pendidikan, sosial ekonomi dan perilaku sehari-hari. ${ }^{5-7}$

Menurut laporan World Health Organisation (WHO) pada tahun 2012 memperkirakan lebih dari 1,5 miliar orang atau $24 \%$ dari populasi dunia terinfeksi dengan cacing yang ditularkan melalui tanah yang ditularkan di seluruh dunia. Lebih dari 270 juta anak usia pra sekolah dan lebih dari 600 juta anak usia sekolah tinggal di daerah di mana parasit ini ditularkan secara intensif. Jumlah kasus infeksi STHs terbanyak dilaporkan di kawasan Sub-Sahara Afrika, benua Amerika, Cina dan Asia Timur.Infeksi terjadi oleh karena ingesti telur cacing dari tanah yang terkontaminasi atau dari penetrasi aktif melalui kulit oleh larva di tanah.Prevalensi protozoa usus pada beberapa negara di dunia masih relatif tinggi.Di Eropa Utara 5\%-20\%, di Eropa Selatan 20\%-51\% dan di Amerika Serikat 4\%-21\%. Di RRC, Mesir, India dan Belanda berkisar antara 10,1\%-11,5\%. Infeksi mayor protozoa usus di Oceania adalah amebiasis, balantidiasis, kriptosporidiosis dan giardiasis. ${ }^{8-12}$

Prevalensi parasit usus di Indonesia masih tergolong tinggi terutama pada penduduk miskin dan hidup di lingkungan padat penghuni dengan sanitasi yang buruk, tidak mempunyai jamban dan fasilitas air bersih tidak mencukupi.Hasil survei Departemen Kesehatan Republik Indonesia di beberapa provinsi di Indonesia menunjukkan prevalensi kecacingan untuk semua umur di Indonesia berkisar antara 40\%-60\%. Di Indonesia, infeksi cacing usus yang paling banyak dijumpai pada manusia adalah Ascaris lumbricoides, Necator americanus, Trichuris trichiura danEnterobius vermicularis, sedangkan Strongyloides stercoralis jarang dilaporkan. Pada penelitian yang dilakukan di Pondok Gede Bekasi pada tahun 2011, hasil penelitian menunjukkan prevalensi infeksi parasit usus pada anak panti asuhan di Pondok Gede Bekasi adalah 37\%, dengan rincian Trichuris trichiura 4\%, Blastocystis hominis 31\%, Giardia lamblia 7\% dan Eschereschia coli 3\%. Infeksi campur Blastocystis hominis dan Trichuris trichiura 2\%, Blastocystis hominis dan G.lamblia 4\%, Blastocystis hominis dan Eschereschia coli $2 \% .^{1,13-17}$

Di Sulawesi Utara, pada penelitian tahun 2015 di RSUP Prof.Dr.R.D.Kandou Manado, didapatkan pada sampel penelitian yang berjumlah 31 anak, ditemukan infeksi protozoa usus yaitu Blastocystis hominis sebanyak 18 (58,1\%) anak. Dilaporkan pula dari beberapa penelitian di Sulawesi Utara, seperti di Kecamatan Poigar Kabupaten Bolaang Mongondow pada tahun 2000 prevalensi askariasis 4,12\%, trikuriasis 5,12\%, dan cacing tambang 12,37\%. Pada peneltian tahun 2010 di SD Katolik dan GMIM 85 di Desa Wori Kecamatan Wori di dapatkan gambaran askariasis 3\%, trikuriasis 2\% dan infeksi cacing tambang 7\%. Daerah Wori memiliki tanah gembur yaitu tanah yang terdiri dari pasir dan humus serta sedikit tanah liat sehingga telur cacing dapat berkembang dengan baik di dalamnya. $^{18,19}$

Tujuan penelitian ini untuk mengetahui gambaran infeksi parasit usus pada anak sekolah dasar di pesisir pantai Kecamatan Wori Kabupaten Minahasa Utara. Pertimbangan pemilihan lokasi adalah karena Desa Budo dan Desa Kima Bajo yang merupakan desa yang berada di Kecamatan Wori, secara geografis terletak di daerah pesisir, di mana daerah tersebut merupakan daerah yang jarang dijamah oleh pemerintah sehingga termasuk dalam kategori neglected disease, yang di dalamnya terdapat penyakit akibat infeksi parasit usus. Berdasarkan data-data di atas juga di dapatkan prevalensi infeksi cacing usus dalam hal ini STHs dan protozoa usus pada anak usia sekolah dasar yang masih cukup tinggi, sehingga cocok dengan pemilihan lokasi Desa Budo dan Desa Kima Bajo yang terletak di pesisir pantai dengan tanah gembur yang baik untuk perkembang-biakan telur cacing, serta higienitas dan sanitasi yang masih buruk akibat penggunaan jamban dan fasilitas air 
bersihkurang mencukupi, yang merupakan kondisi yang dibutuhkan untuk terjadinya infeksi parasit usus.

\section{METODE PENELITIAN}

Penelitian ini merupakan jenis penelitian survei deskriptif.Penelitian ini dilaksanakan di SD GMIM Budo dan SD Negeri Kima Bajo di Kecamatan Wori dan pemeriksaan sampel dilakukan di Laboratorium Parasitologi Universitas Sam Ratulangi Manado.Penelitian ini dilaksanakan selama tiga bulan, pada bulan November 2015 sampai bulan Januari 2016.Total sampel dalam penelitian ini yaitu anak SD GMIM Budo dan SD Negeri Kima Bajo kelas I sampai VI sebanyak 150 anak.Sampel yang berespon didapatkan sebanyak 129 anak yang memenuhi kriteria inklusi.Kriteria inklusi adalah anak SD kelas I sampai VI.Kriteria eksklusi adalah anak SD kelas I sampai VI yang tidak mengembalikan pot.Cara pengambilan data dengan melakukan pengambilan sampel tinja menggunakan pot tinja steril yang diberi label, kemudian sampel tinja diperiksa dengan teknik pemeriksaan langsung (direct) tinja.Data hasil penelitian yang diperoleh melalui pemeriksaan tinja, diolah dan dianalisis dalam bentuk tabel frekuensi dan dibuat dalam bentuk persentase.

\section{HASIL PENELITIAN}

Desa Budo dan Desa Kima Bajo merupakan desa yang berada di Kecamatan Wori. Daerah Wori ini sebelah utara berbatasan dengan Kecamatan Likupang, sebelah timur dengan Kecamatan Dimembe, sebelah selatan dengan Kota Manado, dan sebelah barat dengan Laut Sulawesi. Desa Budo dan Desa Kima Bajo secara geografis terletak di daerah pesisir dan sama seperti daerah lainnya di Kecamatan Wori, DesaBudo dan Desa Kima Bajo memiliki tanah yang gembur, yaitu tanah yang terdiri dari pasir dan humus serta sedikit tanah liat sehingga telur cacing dapat berkembang dengan baik di dalamnya. Higienitas dan sanitasi di dua desa ini juga masih tergolong buruk akibat penggunaan jamban dan fasilitas air bersih kurang mencukupi, yang merupakan kondisi yang dibutuhkan untuk terjadinya infeksi parasit usus.Di Desa Budo dan Desa Kima Bajo terdapat masing-masing satu SD yaitu SD GMIM Budo dan SD Negeri Kima Bajo. Ke dua SD ini terletak di tengah desa.

Penelitian terhadap anak SD GMIM Budo dan SD Negeri Kima Bajo di Kecamatan Wori, Kabupaten Minahasa Utara, pada bulan November 2015 sampai bulan Januari 2016 didapatkan sebanyak 129 anak yang berespon dari 150 anak yang menjadi total sampel.Sampel sebanyak 129 anak yang berespon yaitu dengan mengembalikan pot dengan sampel tinja, yang kemudian di periksa di Laboratorium Parasitologi Fakultas Kedokteran Universitas Sam Ratulangi Manado.

Tabel 1. Pemeriksaan Tinja pada 129 Sampel

\begin{tabular}{ccc}
\hline Sampel & $\mathrm{N}$ & $(\%)$ \\
\hline $\begin{array}{c}\text { Mengandung } \\
\text { cacing usus }\end{array}$ & 6 & 4,7 \\
$\begin{array}{c}\text { Mengandung } \\
\text { protozoa usus }\end{array}$ & 20 & 15,5 \\
$\begin{array}{c}\text { Tidak mengandung } \\
\text { parasit usus } \\
\text { Jumlah }\end{array}$ & 103 & 79,8 \\
\hline
\end{tabular}

Tabel 2. Kasus Infeksi CacingUsus pada 6 sampel positif

\begin{tabular}{ccc}
\hline Jenis Cacing & $\mathrm{N}$ & $(\%)$ \\
\hline Cacing & 6 & 100 \\
tambang & & 0 \\
Cacing lainnya & 0 & 100 \\
Jumlah & 1 & \\
\hline
\end{tabular}

\section{BAHASAN}

Pada penelitan yang dilakukan bulan November 2015 sampai dengan Januari 2016 telah dilakukan penelitian tentang infeksi parasit usus pada anak SD GMIM Budo dan SD Negeri Kima Bajo di Kecamatan Wori. Jumlah anak kelas I sampai kelas VI di SD GMIM Budo dan SD Negeri Kima Bajo yang menjadi total sampel sebanyak 150 anak, sampel yang 
berespon sebanyak 129 anak kelas I sampai kelas VI.

Tabel 3. Kasus Infeksi Protozoa Usus pada 20 sampel positif

\begin{tabular}{ccc}
\hline Jenis Protozoa & $\mathrm{N}$ & $(\%)$ \\
\hline $\begin{array}{c}\text { Entamoeba coli } \\
\text { Chilomastix } \\
\text { mesnili }\end{array}$ & 5 & 25 \\
Blastocystis & 4 & 20 \\
hominis & 4 & 20 \\
$\begin{array}{c}\text { Giardia } \\
\text { lamblia }\end{array}$ & 5 & 25 \\
$\quad$ Infeksi & 2 & 10 \\
campuran & & \\
Jumlah & 20 & 100 \\
\hline
\end{tabular}

Tabel 4. Gambaran Parasit Usus pada 129 sampel

\begin{tabular}{ccc}
\hline Jenis Cacing & $\mathrm{N}$ & $(\%)$ \\
\hline Cacing tambang & 6 & 4,7 \\
Entamoeba coli & 5 & 3,9 \\
Chilomastix & 4 & 3,1 \\
$\quad$ mesnili & & \\
Blastocystis & 4 & 3,1 \\
$\quad$ hominis & 5 & 3,9 \\
Giardia lamblia & 5 & 1,5 \\
Infeksi campuran & 2 & \\
$\quad$ Tidak & & 79,8 \\
mengandung & 103 & \\
parasit usus & & \\
Jumlah & 129 & 100 \\
\hline & &
\end{tabular}

Pot sisa tidak dikembalikan dengan alasan anak tidak buang air besar pada pagi hari atau anak belum buang air besar. Didapatkan informasi dari wakil kepala SD GMIM Budo bahwa anak kelas I sampai kelas VI diberikan obat cacing satu bulan yang sebelumnya oleh petugas puskemas setempat (tidak diketahui jenis obat yang diberikan).

Berdasarkan pemeriksaan tinja didapatkan infeksi cacing usus sebanyak enam kasus $(4,7 \%)$ dan protozoa usus sebanyak 20 (15,5\%) kasus dari 129 sampel yang diperiksa, sedangkan 103 (79,8\%) sampel tidak mengandung parasit usus. Infeksi cacing usus yang didapatkan adalah infeksi cacing tambang 4,7\% dan infeksi protozoa usus yang didapatkan adalah infeksi Entamoeba coli 3,9\%, Chilomastix mesnili 3,1\%, Blastocystis hominis 3,1\%, Giardia lambia3,9\%dan infeksi campuran1,5\% yang terdiri atas infeksi campuran C.mesnili dan E.coli 0,75\% dan C.mesnili dan G.lambia 0,75\%. Infeksi parasit ini terjadi karena daerah Wori, khususnya Desa Budodan Desa Kima Bajo memiliki tanah gembur yaitu tanah yang terdiri dari pasir dan humus serta sedikit tanah liat yang merupakan tempat perkembangbiakan yang baik untuk telur cacing. Higienitas dan sanitasi di ke dua desa ini juga masih tergolong buruk akibat penggunaan jamban dan fasilitas air bersih kurang mencukupi, yang merupakan kondisi yang dibutuhkan untuk terjadinya infeksi parasit usus.

Dari hasil pemeriksaan tinja didapatkan enam sampel (4,7\%) mengandung telur cacing tambang. Apabila dibandingkan dengan penelitian sebelumnya yang dilakukan di daerah Wori yaitu di SD Katolik dan SD GMIM 85 di Desa Wori, maka penelitian di kedua SD tersebut diperoleh hasil infeksi cacing A.lumbricoides 3\%, T.trichiura2\%, cacing tambang $7 \%$ dan yang tidak mengandung cacing $88 \% .{ }^{19} \mathrm{Hal}$ ini menunjukkan bahwa gambaran infeksi cacing usus yang ditularkan melalui tanah di SD GMIM Budo dan SD Negeri Kima Bajo di Kecamatan Wori, Kabupaten Minahasa Utara, lebih rendah dari pada penelitian di SD Katolik dan SD GMIM 85 di Desa Wori, Kecamatan Wori.

Dari pemeriksaan tinja juga didapatkan 20 sampel mengandung protozoa usus (15,5\%). Apabila dibandingkan dengan penelitian yang dilakukan di Pondok Gede Bekasi pada tahun 2011, hasil penelitian menunjukkan prevalensi infeksi parasit usus pada anak panti asuhan di Pondok Gede Bekasi adalah 37\%, dengan rincian Trichuris trichiura 4\%, Blastocystis hominis 31\%, Giardia lamblia 7\% dan Eschereschia coli 3\%. Infeksi campur Blastocystis hominis dan Trichuris trichiura 2\%, Blastocystis hominis dan G.lamblia 4\%, Blastocystis hominis dan Eschereschia coli 2\%. ${ }^{1}$ Pada penelitian tahun 2015 di 
RSUP Prof. Dr. R. D.Kandou Manado, didapatkan infeksi oleh Blastocystis hominis $58,1 \%{ }^{18}$ Hal ini menunjukkan bahwa gambaran infeksi protozoa usus di SD GMIM Budo dan SD Negeri Kima Bajo di Kecamatan Wori, Kabupaten Minahasa Utara, lebih rendah dari pada penelitian di daerah lainnya.

Rendahnya kasus infeksi parasit usus ini diduga berkaitan dengan berbagai faktor yang bisa menyebabkan keadaan tersebut, seperti kesadaran masyarakat termasuk anak-anak akan sanitasi dan higienetas terhadap lingkungan, makanan dan minuman yang sudah baik, serta dilakukannya pemberian obat cacing rutin oleh petugas puskesmas setempat.

\section{SIMPULAN}

Bedasarkan hasil penelitian dan bahasan dapat disimpulkan bahwa

1. Gambaran infeksi parasit usus di SD GMIM Budo dan SD Negeri Kima Bajo di Kecamatan Wori, Kabupaten Minahasa Utara, didapatkan 4,7\% infeksi cacing usus dan 15,5\% infeksi protozoa usus.

2. Infeksi cacing usus yang didapatkan adalah infeksi cacing tambang dan infeksi protozoa usus yang didapatkan adalah infeksi oleh Entamoeba coli, Chilomastix mesnili, Blastocystis hominis, Giardia lambia dan infeksi campuran.

\section{SARAN}

Untuk menghindari dan mencegah terjadinya penyebaran infeksi parasit usus maka disarankan pengobatan anak SD GMIM Budo dan SD Negeri Kima Bajo di Kecamatan Wori, Kabupaten Minahasa Utara, yang terinfeksi parasit usus.

\section{DAFTAR PUSTAKA}

1. Darnely, Saleha S. Infeksi parasit usus pada anak panti asuhan di Pondok Gede Bekasi. J Indon Med Assoc. 2011;61:347-51.

2. Silitonga MM, Sudharmono U, Hutasoit M. Prevalensi kecacingan pada murid sekolah dasar negeri di desa
Cihanjuang Rahayu Parongpong Bandung Barat. Jurnal FK Unpad. [serial on the internet]. 2009 [cited 2015 Sept 24]. Available from: http://journal.fk.unpad.ac.id/index.ph p/mkb/article/viewFile/260/pdf_119

3. Samosir A. Latar belakang: infeksi cacing [homepage on the internet]. 2013 [cited 2015 Sept 24]. Available from: http://repository.usu.ac.id/bitstream/1 23456789/38033/5/Chapter\%20I.pdf

4. Chadijah S, Sumolang PPF, Veridiana NN. Hubungan pengetahuan, perilaku, dan sanitasi lingkungan dengan angka kecacingan pada anak sekolah dasar di kota Palu. Media Litbangkes. 2014;24:50-6.

5. Soedarto. Helmintologi kedokteran. Edisi ke 2. Jakarta: EGC, 1995.

6. Haryanti E. Helmitologi kedokteran. Medan: Bagian Parasitologi Fakultas Kedokteran USU, 1993.

7. Nilamsari L. Perbedaan prevalensi protozoa usus antara siswa sd pedesaan dengan perkotaan dan hubungannya dengan faktor risiko. [Skripsi]. Yogyakarta: FK Universitas Muhammadiyah Yogyakarta; 2012.

8. WHO. Soil-transmitted helminth infections [homepage on the internet]. c2015 [updated 2015 Mei; cited 2015 Sept 24]. Available from: http://www.who.int/mediacentre/facts heets/fs366/en/

9. Resnhaleksmana E. Prevalensi nematoda usus golongan soil transmitted helminthes (sth) pada peternak di lingkungan gatep kelurahan Ampenan Selatan. Media Bina Ilmiah 45. 2014;8:1-4.

10.Ratag BT, Maramis FRR, Dareda K. Hubungan antara higiene perorangan dengan infestasi cacing usus pada siswa sekolah dasar negeri 119 Manado. Buletin IDI Manado [serial on the internet]. 2012 [cited 2015 Sept 24]; 1(1). Available from: http://idimanado.org/2012/07/2833.ht $\mathrm{ml}$

11.Lengkong BR, Joseph WBS, Pijoh VD. Hubungan antara higiene perorangan dengan infestasi cacing pada pelajar sekolah dasar negeri 47 kota Manado[serial on the internet]. 2013 [cited 2015 Sept 24]. Available from: 
http://fkm.unsrat.ac.id/wpcontent/uploads/2013/08/JurnalBrian-R.-Lengkong-091511146KESLING.pdf

12.Kevin K, James SM, Mark P, Alex L, Peter JH. Neglected tropical diseases of Oceania: review uf their prevalence, distribution and opportunities for control. PLOS Neglected Tropical Diseases. 2013;7:1-9.

13. Ganda S. Parasitologi kedokteran. Edisi 4. Jakarta: Badan Penerbit FKUI, 2011.

14.Hökelek M. Nematodes infections [homepage on the internet]. c2015 [updated 2015 Jan 22; cited 2015 Sept 24]. Available from: http://emedicine.medscape.com/articl e/224011-overview

15. Matei YT, Rampengan N, Warouw SM. Hubungan infestasi cacing yang ditularkan melalui tanah dan eosinofilia pada siswa sd gmim Buha
Manado. Jurnal e-Biomedik (eBM). 2013;1:651-5.

16. Natadisastra D, Agoes R. Parasitologi kedokteran ditinjau dari organ tubuh yang diserang. Edisi 1. Jakarta: EGC, 2009.

17.CDC. About parasites [homepage on the internet]. c2015 [updated 2015 Mar 05; cited 2015 Sept 24]. Available from:http://www.cdc.gov/parasites/ab out.html

18.Mona CUA, Jeanette ICM, Rocky W. Gambaran gejala dan tanda klinis diare akut pada anak karena Blastocystis hominis. Jurnal e-Clinic (eCl). 2015;3:503-9.

19.Moniaga F. Gambaran perilaku dan lingkungan terhadap penyebaran cacing usus yangditularkan melalui tanah pada murid sd katolik dan sd gemim 85 di desa wori kec. Wori kab. Minahasa Utara. [Skripsi]. Manado: FKUNSRAT; 2011. 